Thomas Hurst ${ }^{3}$ DVsC, David Johnson ${ }^{1,3}$ MD, Bibiana Cujec ${ }^{3} \mathrm{MD}$, Dorothy Thomson ${ }^{4} \mathrm{MD}$, Taras Mycyk $^{4}$ MD, Brent Burbridge ${ }^{2}$ MD, Irvin Mayers ${ }^{5}$ MD FRCP

\title{
Depletion of activated neutrophils by a filter during cardiac valve surgery
}

Purpose: To determine whether inclusion of a neutrophil-specific filter into the extracorporeal circuit during open heart valve surgery alters postoperative outcomes.

Methods: Convenience sampling of 24 patients undergoing elective open heart valve surgery between fuly 1993 and June 1994. Patients were randomized to a neutrophil-specific filter $(n=11)$ or to a standard blood fiter $(n=13)$ during cardiopulmonary bypass.

Results: Neutrophil-specific filter diminished $(P<0.02)$ the expression of $C D \mid 8$, a neutrophil surface adhesion molecule, at I $(84.5 \pm 4.2$ vs $94.8 \pm 3.8 \%), 4(80.0 \pm 4.2$ vs $95.1 \pm 3.9 \%)$ and $24 \mathrm{hr}(75.2 \pm 4.2$ vs $98.2 \pm$ $3.9 \%)$ post- operatively compared with standard filter. Total white blood cell count, neutrophil count. and proinflammatory cytokines ( $\mathrm{LL}-6, \mathrm{IL}-8)$ were similar between groups at all times. Measured outcomes including: $\mathrm{PaO}_{2}$. cardiac index, ejection fraction, haemodynamic variables, use of inotropes, spirometry (FEV,$F V C$ ). and hospitalization duration were similar between groups.

Conclusions: Inclusion of the neutrophil filter during open heart valve surgery selectively depletes activated neutrophils. There were no other detectable differences between the two groups and the use of a neutrophilspecific filter in routine clinical practice for patients undergoing open heart valve surgery is not supported.

Objectif : Déterminer si l'ajout au circuit extracorporel d'un filtre spécifique aux neutrophiles pendant une chirurgie valvulaire modifiait les résultats de l'intervention

Méthodes : Un échantillonnage de 24 patients subissant une intervention valvulaire à coeur ouvert entre juillet 1993 et juin 1994. Les patients ont été répartis aléatoirement à un circuit extracorporel incluant un filtre spécifique aux neutrophiles $(n=\mid 1)$ ou un filtre standard $(n=\mid 3)$.

Résultats : Le filtre spécifique aux neutrophiles a diminué l'expression de $C D \mid 8$, une molécule adhésive de surface, une heure $(84,5 \pm 4.2$ vs $98.8 \pm 3.8 \%)$, quatre heures ( $80 \pm 4.2$ vs $95,1 \pm 3.9 \%$ ) et 24 heures $(75.2 \pm 4.2$ vs $98.2 \pm 3.9 \%)$ après l'opération comparativement au filtre standard. Le décompte total des globules blancs, des neutrophiles et des cytokines pro-inflammatoires (IL-6, IL8) étaient à tous les moments identiques

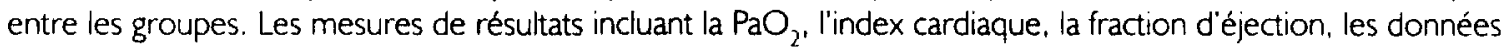
hémodynamiques, l'utilisation d'inotropes, la spirométrie (VEMS. CVF) et la durée du séjour hospitalier étaient identiques entre les groupes.

Conclusion : L'ajout d'un filtre spécifique aux neutrophiles pendant la chirurgie à coeur ouvert épuise sélectivement les neutrophiles activés. Aucune autre différence n'est discernable entre les groupes. L'utilisation courante de fitres spécifiques aux neutrophiles en clinique chez des patients soumis à une chirurgie valvulaire à coeur ouvert n'est pas justifiée.

From the Departments of Anaesthesia, ${ }_{1}^{1}$ Medical Imaging, ${ }^{2}$ Medicine ${ }^{3}$ and Surgery, ${ }^{4}$ University of Saskatchewan, Saskatoon, Saskatchewan, Canada and Department of Medicine, ${ }^{5}$ University of Alberta, Edmonton, Alberta, Canada. Address Correspondence to: Dr. D. Johnson, Box 95, Royal University Hospital, 103 Hospital Drive, Saskatoon, SK, S7N 0W8 TEL: (306) 655-2053; FAX: (306) 966-8021; e-mail:davidj@duke.usask.ca

Accepted for publication October 11, 1996. 


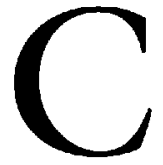

ARDIOPULMONARY bypass (CPB) causes marked alterations in organ perfusion and metabolism. ${ }^{1,2}$ The host of mediators released during $\mathrm{CPB}$ has been catalogued ${ }^{3}$ and although the clinical importance of any one mediator remains uncertain, some of these may cause end organ dysfunction. Interleukin-6 (IL-6), a cytokine with recognized cardiodepressant activity ${ }^{4}$ is released as is interleukin-8 (IL-8), a potent neutrophil chemoattractant. ${ }^{5}$ Circulating mediators are not the only agents which may cause organ injury following CPB. Following CPB neutrophil sequestration within lung tissue has been documented ${ }^{6}$ and this neutrophil infiltration is associated with organ dysfunction. ${ }^{7}$ Cardiac performance may also be adversely affected following perfusion with solutions containing activated neutrophils. ${ }^{8,9}$ We have previously examined whether reducing circulating neutrophils by including a neutrophil-specific filter in the extracorporeal perfusion circuit could improve clinical outcomes following elective coronary artery bypass surgery. ${ }^{10} \mathrm{We}$ found that, in this low-risk group, inclusion of the neutrophil-specific filter was associated with a transient improvement in haemodynamic function but it did not alter any other measured clinical outcome. We wondered if the filter and activated neutrophil depletion might be of more benefit in overall higher operative risk patients. ${ }^{11,12} \mathrm{We}$ therefore decided to study patients undergoing elective heart valve surgery since these individuals have longer extracorporeal perfusion times which may potentiate maximum leukocyte reperfusion injury. We prospectively examined clinical outcomes, levels of selected proinflammatory cytokines, and cardiac performance by echocardiography in these patients and followed them to the time of discharge from hospital.

\section{Methods and Materials}

\section{Patient Assessment and Measurements}

The study was approved by our university ethics committee. All patients scheduled for elective open-heart valve surgery between July 1993 and June 1994 were eligible. Patients were excluded if we could not obtain informed consent, or if they were undergoing emergency surgery. Preoperative assessment included: a respiratory questionnaire to assess preoperative pulmonary symptoms," a chest X-ray; bedside spirometry (Welch Allyn, Pneumocheck spirometry \#61000, Skaneateles Falls, NY) to measure forced vital capacity (FVC) and forced expiratory volume in one second $\left(\mathrm{FEV}_{1}\right)$. Angina severity was graded by a standard scale. $^{13}$ Intraoperative data included: aortic crossclamp time, total cardiopulmonary bypass time, and fluid balance. Timing of haemodynamic measurements or sampling of arterial blood was obtained preoperatively, after anaesthetic induction, time of aortic $\mathrm{x}$-clamp, one hour post-operatively, four hours postoperatively and at approximately $24 \mathrm{hr}$ after surgery. All blood samples and measurements were obtained during mechanical ventilation with $100 \%$ oxygen. Haemodynamic measurements included: systemic arterial pressure $\left(\mathrm{P}_{S A}\right)$, right atrial pressure $\left(\mathrm{P}_{\mathrm{RA}}\right)$, pulmonary artery pressure $\left(\mathrm{P}_{\mathrm{PA}}\right)$, pulmonary capillary wedge pressure $\left(\mathrm{P}_{\mathrm{CWP}}\right)$, and cardiac index $(\mathrm{CI})$. Arterial and mixed venous blood samples were directly analyzed for blood gases (NOVA, Boston, MA) and oxyhaemoglobin saturation (CIBA Corning Model 5000 , Boston, MA). Blood samples were obtained for other measurements included: white blood cell count (WBC), neutrophil count, platelet count, interleukin 6 (IL-6), interleukin 8 (IL-8), interleukin 6 soluble receptor (IL-6SR), and neutrophil expression of the cell surface adhesion molecules CDIlb and CD18. Weight, chest X-ray, fluid balance, $\mathrm{FEV}_{1}$ and FVC were measured on the second day post-operatively, fifth day post-operatively and at the time of discharge.

Echocardiography was obtained before surgery and then repeated before discharge. Fractional shortening (FAS) of the left ventricle was calculated as:

$F A S=\underline{L V}$ diastole dimension $-\mathrm{LV}$ systole dimension

$$
\mathrm{LV} \text { diastole dimension }
$$

Values for volume were then derived from the Teichholz formula ${ }^{14}$ and ejection fraction (EF) calculated substituting the calculated volumes for dimension measurement. Wall motion abnormalities were described as being present $(+)$ or absent $(-)$ by a single investigator $(\mathrm{BC})$, blinded to treatment.

\section{Experimental Protocol}

We enrolled 24 patients and followed them to the time of hospital discharge. Intraoperatively, surgery and anaesthesia were based upon the practices of the two referral surgeons and attending anaesthetists. Cardioplegia solutions have been standardized and thus did not differ between patients. Anaesthesia consisted of opioid (sufentanil 3-5 $\mu \mathrm{g} \cdot \mathrm{kg}^{-1}$ ), sedative (propofol l-2 $\mathrm{mg} \cdot \mathrm{kg}^{-1}$, midazolam $0.01-0.13 \mathrm{mg} \cdot \mathrm{kg}^{-1}$ ), muscle relaxant (pancuronium $0.15-0.3 \mathrm{mg} \cdot \mathrm{kg}^{-1}$, vecuronium $0.1-0.3 \mathrm{mg} \cdot \mathrm{kg}^{-1}$ ) and an inhalational agent (isoflurane). Blood cardioplegia (antegrade) was administered every $15 \mathrm{~min}$ with systemic cooling to $24-28^{\circ} \mathrm{C}$. Patients were randomized at the time of surgery to receive a standard blood filter (Pall $^{\mathrm{R}}$ Autovent SP, MacLean Medical, Toronto, Canada) or a neutrophil-specific filter (Pall ${ }^{\mathbb{R}}$ LG-6, MacLean Medical, Toronto, Canada). 
The filters were not distinguishable without close visual inspection. All investigators were blinded throughout the study to type of filter each subject received.

A single radiologist blinded to treatment scored all chest $\mathrm{X}$-rays using a standard grading system ${ }^{15}$ : 0 - no atelectasis, 1 - plate atelectasis, 2 - subsegmental atelectasis, 3 - segmental atelectasis, 4 - lobar atelectasis. IL-6, IL-6SR and IL-8 were measured by radioimmunoassay (ELISA Medgenics Diagnostics, Brussels, Belgium). Assessment of the neutrophil cell surface adhesion complexes CD1 lb and CD18 were obtained by flow cytometry (Facscan Flow Cytometer (Becton Dickenson, San Jose, CA) using specific anti-CD18 and anti-Cdllb murine antibodies. The neutrophils were stained with a control antibody to set a threshold of fluorescence, such that less than $2 \%$ of the cells exceeded the threshold. The percentages of neutrophils with specific antiCD1 lb or anti-CD18 antibodies which exceeded this threshold were recorded as the percentage positive.

\section{Statistics}

Variables were compared over time and between groups by two-way repeated measures analysis of variance (ANOVA). When the F statistics showed a significant difference, $t$-tests were used to determine which groups were different. Sidak's multiplicative inequality was used to correct the number of comparisons made between groups. The assumptions that the residuals were normally distributed and equality of residual variances were tested using the Shapiro Wilks Test and the Schweiders Test, respectively. Dichotomous data was compared by Chi square and when any cell count was less than 5, a Fisher Exact Test was used. A P value less than 0.05 was considered to show a significant difference. All data are reported as mean \pm standard deviation.

Our study sample size selection was based upon published data ${ }^{16}$ demonstrating differences in outcomes in patients using the leukocyte filter and upon our previous study. ${ }^{10}$ In order to achieve a power of 0.8 , setting $\alpha$ at 0.05 , a sample size of 10 patients per group would be required to distinguish a $10 \mathrm{mmHg}$ difference in mean arterial pressure or difference of $\mathbf{5 0}$ $\mathrm{mmHg}$ in $\mathrm{A}-\mathrm{aO}_{2}$ gradient between the neutrophilfilter treated group and the control group. We did not use expression of interleukins as a surrogate outcome in estimating sample size as an effect of filter after extracorporeal oxygenation has been demonstrated despite similar concentrations of interleukins. ${ }^{17}$

\section{Results}

\section{Demographic data and Clinical Course}

The two groups were similar in baseline characteristics (Table I). Preoperative medication usage, respiratory
TABLE I Demographic data

\begin{tabular}{|c|c|c|c|}
\hline & & Standard Filter & Leukocyte Filter \\
\hline & & $n=13$ & $n=11$ \\
\hline Age (yr) & & $61 \pm 15$ & $63 \pm 14$ \\
\hline $\begin{array}{ll}\text { Sex } & - \text { Male } \\
& - \text { Female }\end{array}$ & & & $\begin{array}{l}4 \\
7\end{array}$ \\
\hline Body Mass Inde & $\left.\mathrm{Kg} \cdot \mathrm{m}^{-2}\right)$ & $25 \pm 6.8$ & $27.7 \pm 3.5$ \\
\hline $\begin{array}{l}\text { Left Ventricular } \\
\text { Fraction }\end{array}$ & ction & & \\
\hline & & $\begin{array}{l}8 \\
5\end{array}$ & $\begin{array}{l}7 \\
4\end{array}$ \\
\hline $\begin{array}{l}\text { Saphenous Vein } \\
\text { (median, range) }\end{array}$ & & $1(0-3)$ & $1(0-3)$ \\
\hline Dyspnea Grade & 0 & 2 & 0 \\
\hline & 1 & 2 & 2 \\
\hline & 2 & 6 & 2 \\
\hline & 3 & 0 & 3 \\
\hline & 4 & 3 & 4 \\
\hline $\begin{array}{l}\text { Extra-corporeal } \\
\text { (min) }\end{array}$ & genation & $143 \pm 24$ & $178 \pm 83$ \\
\hline X-Clamp Time ( & & $104 \pm 22$ & $123 \pm 56$ \\
\hline Mitral Valve Sur & & 4 & 2 \\
\hline Aortic Valve Sur & & 6 & 6 \\
\hline Aortic/Mitral V & Surgery & 3 & 3 \\
\hline Cough & & $10^{*}$ & 3 \\
\hline Past Smoker & & 6 & 5 \\
\hline
\end{tabular}

*significant difference $(P<0.05)$ between groups. Left ventricular ejection fraction assessed by ventriculogram and dyspnea grade by ACC-AHA Task Force Report ${ }^{26}$

symptoms and cardiac symptoms were also similar between groups. Intraoperatively, extracorporeal oxygenation time, cross-clamp time, number of saphenous grafts, and specific type of valvular surgery were similar between groups (Table I).

There were no differences between standard and leukocyte groups in our measured clinical outcomes. Total length of hospitalization $(8.3 \pm 2.3$ vs $8.5 \pm 2.6$ days) and ICU stay $(1.7 \pm .5$ ps $2.5 \pm 1.7$ days $)$ were similar. Haemoglobin concentrations and platelet counts were decreased $(P<0.05)$ at one-hour and remained decreased throughout the intensive care unit stay in both groups (Table II). White blood count and neutrophil counts were similarly decreased during extracorporeal oxygenation. By one hour after CPB and continuing up to two days postoperatively both neutrophil counts and white blood cell counts were elevated compared to admission. These values returned to admission values by the time of hospital discharge (Figure 1).

The number of patients receiving inotropes was similar $(P=.877)$ comparing the standard filter group $(n=11)$ and the neutrophil-specific filter group 
TABLE II Biochemical physiology outcomes

\begin{tabular}{|c|c|c|c|c|c|c|c|c|}
\hline & \multicolumn{2}{|l|}{ Induction } & \multicolumn{2}{|l|}{ 1-hour } & \multicolumn{2}{|l|}{ 4-bour } & \multicolumn{2}{|l|}{ 24-bourr } \\
\hline & $S$ & $L$ & $S$ & $L$ & $S$ & $L$ & $S$ & $L$ \\
\hline $\begin{array}{l}\text { Haemoglobin } \\
\left(\mathrm{mg} \cdot \mathrm{kg}^{-1}\right)\end{array}$ & $110 \pm 17$ & $106 \pm 21$ & $78^{*} \pm 14$ & $74^{\star} \pm 17$ & $97 \pm 15$ & $96 \pm 15$ & $96 \pm 13$ & $98 \pm 11$ \\
\hline $\begin{array}{l}\text { Platelets } \\
\left(10^{9} \cdot L^{-1}\right)\end{array}$ & $189 \pm 60$ & $174 \pm 61$ & $104^{*} \pm 30$ & $96^{*} \pm 27$ & $129 \pm 39$ & $112 \pm 36$ & $126 \pm 34$ & $115 \pm 41$ \\
\hline $\begin{array}{l}\text { CPK } \\
(\mu \circ) \cdot L^{-1)}\end{array}$ & $42 \pm 25$ & $53 \pm 37$ & $286 \pm 103$ & $427 \pm 179$ & $405 \pm 149$ & $695 \pm 405$ & $489 \pm 216$ & $900 \pm 700$ \\
\hline $\begin{array}{l}\mathrm{CPK} \\
\left(\mu \mathrm{ol} \cdot \mathrm{L}^{-1}\right)\end{array}$ & 0 & 0 & $41^{*} \pm 15$ & $56^{*} \pm 12$ & $39^{\star} \pm 15$ & $64^{*} \pm 51$ & $27 \pm 18$ & $47 \pm 41$ \\
\hline $\begin{array}{l}\text { IL-6 SR } \\
\left(\mathrm{mg} \cdot \mathrm{ml}^{-1}\right)\end{array}$ & $32.5 \pm 2.8$ & $30.6 \pm 3.8$ & $23.2^{\star} \pm 1.7$ & $23.1^{*} \pm 2.5$ & $27.1 \pm 1.6$ & $27.5 \pm 1.9$ & $32.1 \pm 3.2$ & $29.5 \pm 2.8$ \\
\hline
\end{tabular}

${ }^{\star} P<0.05$ compared with induction and 21 hr periods within each group. $S$ refers to standard filter and $\mathrm{L}$ refers to leukocyte filter.

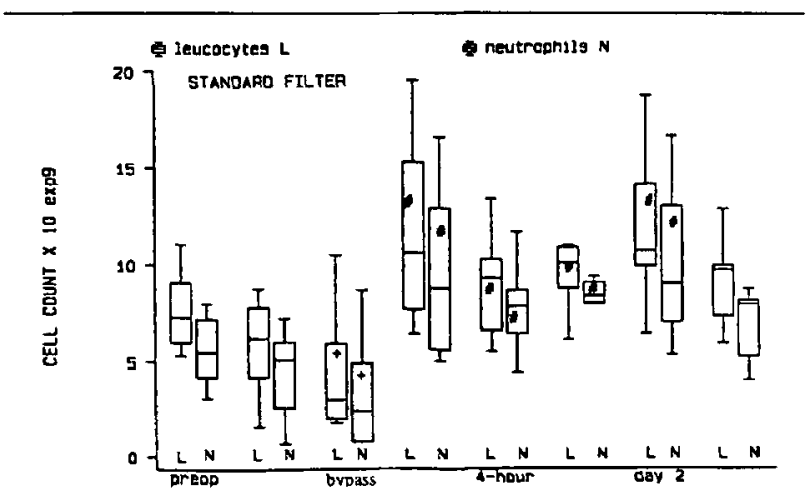

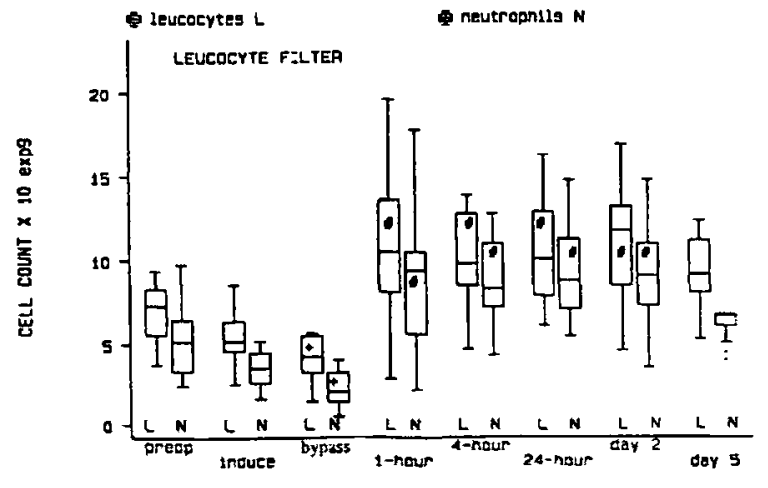

FIGURE 1 Total leukocyte and neutrophil counts (cell count $\times 10^{9}$ cells. $\left.1^{-1}\right)$ in the standard filter and neutrophil filter groups over course of experiments. The box plot illustrates 25 th, 50th, and 75th percentiles and the whiskers denore the standard deviation. + denotes $P<0.05$ in comparison with all other periods and \# denotes $P<0.05$ in comparison with preoperative periad. No differences between standard and leukocyte filter groups were noted.

$(\mathrm{n}=10)$. None of the patients had CPK-MB fraction greater than $10 \%$ of total CPK (Table II). IM CPK$\mathrm{MB}$ was increased at one and four hours post-operatively compared with induction but was similar between groups. No patient had ECG evidence of a new $Q$ wave myocardial infarction. Pulmonary function as measured by spirometry (FVC, FEV ) and atelectasis scores on CXR were also similar between groups (Table IV).

\section{Cytokines and Neutrophil Adhesion Molecules}

In both groups, IL-6 and IL-8 concentrations progressively increased up to four hours post-ICU admission and at $24 \mathrm{hr}$ had still not returned to baseline values (Figure 2). IL-6SR (Table II) decreased when extracorporeal perfusion was initiated and then remained constant up to $24 \mathrm{hr}$ post-operatively. Values of IL- 6 and IL- 8 were similar between the neutrophil-specific and standard filter groups (Figure 2). Expression of CD$11 \mathrm{~b}$ was similar between both groups at all measurement times (Figure 3). Expression of CD-18 neutrophil was reduced at 1,4 and $24 \mathrm{hr}$ after surgery in the neutrophil-specific filter group compared to the standard filter group (Figure 3). As well, a t-test of percent change between baseline and $24 \mathrm{hr}$ postoperatively demonstrated $(P<0.017)$ differences in CD18 expression in the standard $(14.0 \pm 22.5 \%)$ and leukocyte filter $(-2.8 \pm 6.5 \%)$ respectively.

\section{Haemodynamic data and Gas Exchange}

Mean arterial pressure was decreased at induction compared with $24 \mathrm{hr}(P<0.05)$ in all patients, but was not different between groups. Cardiac index, systemic vascular resistance, pulmonary vascular resistance, mean pulmonary artery pressure pulmonary artery occlusion pressure, and central venous pressure were similar between groups at all times (Table III). Echocardiographic assessments were similar between groups when described either descriptively (presence of absence of new wall motion abnormalities) or by measurement of FAS and EF. 
TABLE III Haemodynamic and blood gas physiological outcomes

\begin{tabular}{|c|c|c|c|c|c|c|c|c|}
\hline & \multicolumn{2}{|l|}{ Induction } & \multicolumn{2}{|l|}{ 1-bour } & \multicolumn{2}{|l|}{ 4-hour } & \multicolumn{2}{|l|}{ 24-bour } \\
\hline & $S$ & $L$ & $S$ & $L$ & $S$ & $L$ & $s$ & $L$ \\
\hline $\begin{array}{l}\mathrm{P}_{\mathrm{SA}} \\
(\mathrm{mmHg})\end{array}$ & $73^{*} \pm 10$ & $75^{\star} \pm 11$ & $78 \pm 11$ & $81 \pm 9$ & $83 \pm 13$ & $79 \pm 12$ & $89 \pm 15$ & $80 \pm 12$ \\
\hline $\begin{array}{l}P_{\mathrm{PA}} \\
(\mathrm{mmHg})\end{array}$ & $24 \pm 6$ & $26 \pm 9$ & $22 \pm 6$ & $27 \pm 8$ & $25 \pm 7$ & $28 \pm 10$ & $25 \pm 7$ & $28 \pm 10$ \\
\hline $\begin{array}{l}\mathrm{P}_{\mathrm{CWr}} \\
(\mathrm{mmHg})\end{array}$ & $16 \pm 5$ & $18 \pm 7$ & $13 \pm 4$ & $17 \pm 6$ & $15 \pm 6$ & $19 \pm 6$ & $15 \pm 5$ & $19 \pm 6$ \\
\hline $\begin{array}{l}\mathrm{P}_{\mathrm{RA}} \\
(\mathrm{mmHg})\end{array}$ & $10 \pm 6$ & $11 \pm 7$ & $9 \pm 3$ & $12 \pm 3$ & $11 \pm 4$ & $13 \pm 4$ & $13 \pm 4$ & $12 \pm 4$ \\
\hline $\begin{array}{l}\mathrm{CI} \\
\left(\mathrm{L} \cdot \mathrm{min}^{-1}\right)\end{array}$ & $2.1 \pm 1.0$ & $2.0 \pm 1.0$ & $2.4 \pm 1.3$ & $2.1 \pm 1.1$ & $2.3 \pm 1.1$ & $2.0 \pm 1.1$ & $2.4 \pm 0.9$ & $2.4 \pm 1.2$ \\
\hline $\begin{array}{l}\text { SVR } \\
\left(\text { dynes } \cdot \mathrm{sec}^{-1} \cdot \mathrm{cm}^{-5}\right)\end{array}$ & $1303 \pm 386$ & $1606 \pm 737$ & $1403 \pm 610$ & $1472 \pm 367$ & $1611 \pm 892$ & $1577 \pm 386$ & $1403 \pm 392$ & $1297 \pm 289$ \\
\hline $\begin{array}{l}\text { PVR } \\
\text { (dynes } \cdot \mathrm{sec}^{-1} \cdot \mathrm{cm}^{-5} \text { ) }\end{array}$ & $159 \pm 106$ & $191 \pm 132$ & $183 \pm 134$ & $138 \pm 102$ & $208 \pm 137$ & $231 \pm 124$ & $201 \pm 148$ & $243 \pm 133$ \\
\hline $\begin{array}{l}\mathrm{A}-\mathrm{aO}_{2} \text { gradient } \\
(\mathrm{mmHg})\end{array}$ & $210^{*} \pm 128$ & $210^{\star} \pm 129$ & $295 \pm 130$ & $262 \pm 127$ & $308 \pm 104$ & $283 \pm 128$ & $299 \pm 148$ & $326 \pm 135$ \\
\hline$\dot{\mathrm{Q}} \mathrm{s} / \mathrm{Q} \mathrm{t}$ & $18 \pm 7$ & $18 \pm 7$ & $26^{\star} \pm 10$ & $25^{\star} \pm 8$ & $15 \pm 4.7$ & $15 \pm 7$ & $16 \pm 6$ & $16 \pm 8$ \\
\hline
\end{tabular}

* $P<0.05$ compared with 24-hr period within each group. $S$ refers to standard filter and $\mathrm{L}$ refers to leukocyte filter.

Mean arterial $\left(\mathrm{P}_{\mathrm{SA}}\right)$, puilmonary artery $\left(\mathrm{P}_{\mathrm{pA}}\right)$, wedge $\left(\mathrm{P}_{\mathrm{CWP}}\right)$, right atrial $\left(\mathrm{P}_{\mathrm{RA}}\right)$ pressures; caridac index $(\mathrm{CI})$, systemic (SVR) and pulmonary (PVR) vascular resistances and shunt (Qs/Qt)
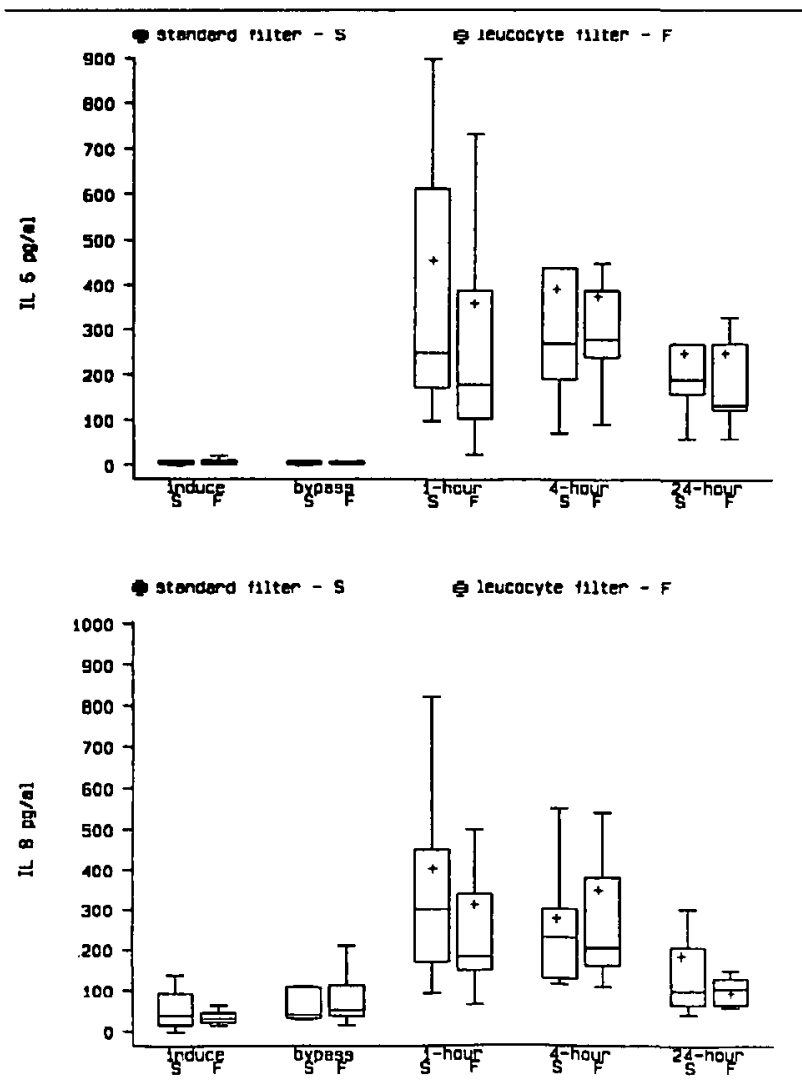

FIGURE 2 IL-6 and IL-8 concentrations during extracorporeal oxygenation and 1,4 , and $24 \mathrm{hr}$ in ICU. Where \# denotes $P<0.05$ comparing standard filter with leukocyte filter. The box plot illustrates $25 \mathrm{th}, 50 \mathrm{th}$, and 75 th percentiles and the whiskers denote the standard deviation. + denotes $P<0.05$ in comparison with the initial period.

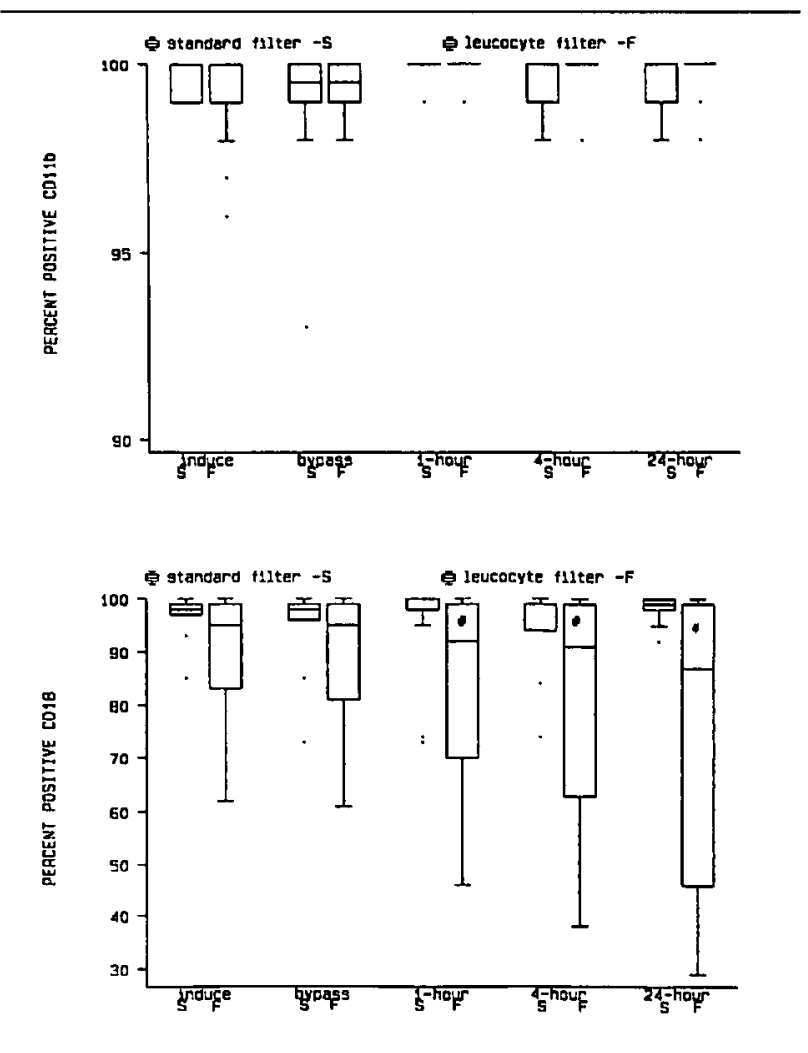

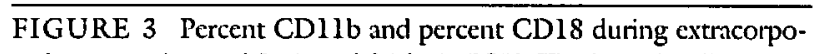
real oxygenation and 1,4 , and $24 \mathrm{hr}$ in ICU. The box plot illustrates 25th, 50th, and 75th percentiles and the whiskers denote the standard deviation. \# denotes $P<0.05$ comparing standard filter with leukocyte filter. Where + denotes $P<0.05$ in comparison with the initial period. 
TABLE IV Pulmonary function test and echocardiogram

\begin{tabular}{|c|c|c|c|c|}
\hline & $\begin{array}{l}\text { Preoperative } \\
S\end{array}$ & $L$ & $\begin{array}{l}\text { Discharge } \\
S\end{array}$ & $L$ \\
\hline $\mathrm{FEV}_{1}(\mathrm{~L})$ & $2.1 \pm 0.8$ & $1.6 \pm 0.5$ & $1.0^{\star} \pm 0.4$ & $0.7^{\star} \pm 0.5$ \\
\hline FVC (L) & $2.8 \pm 0.9$ & $2.3 \pm 0.5$ & $1.4^{*} \pm 0.6$ & $1.0^{\star} \pm 0.6$ \\
\hline $\begin{array}{l}\text { Wall Motion } \\
\text { Abnormality (Patients) }\end{array}$ & 4 & 4 & 6 & 6 \\
\hline $\begin{array}{l}\text { Fractional Shortening } \\
\text { (\%) }\end{array}$ & $0.30 \pm 0.12$ & $0.35 \pm 0.18$ & $0.25^{*} \pm 0.11$ & $0.32^{\star} \pm 0.13$ \\
\hline $\begin{array}{l}\text { Ejection Fraction } \\
\text { (\%) }\end{array}$ & $0.46 \pm 0.1$ & $0.45 \pm 0.19$ & $0.45^{*} \pm 0.18$ & $0.42^{*} \pm 0.13$ \\
\hline Atclectasis Score & $0.15 \pm 0.31$ & $0.18 \pm 0.34$ & $3.0^{*} \pm 1.1$ & $3.1^{*} \pm 1.4$ \\
\hline
\end{tabular}

$S$ refers to standard filter and $\mathrm{L}$ refers to leukocyte filter, ${ }^{*} P<0.05$ compared with preoperative values within each group. Atelectasis score is defined within text.

Intrapulmonary shunt ( $\dot{\mathrm{Q}} / \mathbf{\mathrm { Q }} \mathrm{t})$ was increased at four hours compared with baseline values but was similar between both groups. The alveolar to arterial difference for oxygen $\left(\mathrm{A}-\mathrm{aDO}_{2}\right)$ was decreased at induction compared with all other periods postoperatively (Table IV). One patient in each group received antiarrhythmic drugs $(P=0.54)$. Total mediastinal blood loss was similar in the two groups $(663 \pm 353 v s$ $505 \pm 262 \mathrm{ml} ; P=0.57$ ).

\section{Discussion}

\section{Neutrophil-Specific Filters}

Extracorporeal oxygenation may cause neutrophil activation by generation of complement ${ }^{3}$ which may then activate neutrophils and platelet activations. ${ }^{18}$ Once activated, neutrophils can cause injury via free radical production, induction of elastase or production of vasoactive mediators (e.g., eicosanoids, cytokines). ${ }^{19,20}$ Depletion of activated neutrophils during extracorporeal bypass has been attempted using neutrophil filters ${ }^{17,21}$ as well as by plasmapheresis. ${ }^{22}$ Use of neutrophil-specific filters has been associated with improved oxygenation, ${ }^{23}$ improved haemodynamics, reduction in myocardial stunning ${ }^{24}$ and decreased free radical production. ${ }^{21}$ We have previously shown, in a canine model of $\mathrm{CPB}$, that using a neutrophil-specific filter could reduce the numbers of circulating activated neutrophils, as assessed by chemiluminescence, when compared with a standard blood filter. ${ }^{16}$ As well, in a previous study of humans undergoing CABG surgery, we noted transient improvements in intrapulmonary shunt and mean blood pressure in patients treated with a neutrophil filter compared with a standard blood filter respectively. ${ }^{10}$ Although we concluded that in low-risk, elective CABG surgery patients the neutrophil-specific filter offered no long-lasting clinical benefit, we speculated that in higherrisk patients the filters might be beneficial. We have, therefore, evaluated the clinical effects of a neutrophil- specific filter in patients undergoing heart valve surgery in whom $\mathrm{CPB}$ times would be longer and the extent of neutrophil activation could be expected to be greater than in CABG patients. We found that the valve surgery patients required an average of over 50 min more extracorporeal oxygenation time and $\mathbf{3 0}$ min more crossclamp time than did our patients in the previous study having $C A B G$ alone. We found that inclusion of the neutrophil filter did not reduce the total number of circulating neutrophils when compared with the standard non-specific blood filter. Following cardiopulmonary bypass all patients showed large but similar increases in circulating neutrophils. This differed from our previous study where the circulating neutrophil count was reduced in the group treated with the neutrophil filter. We believe that the ability of the filter to remove neutrophils may have been exceeded by the long extracorporeal circulation time which the valve surgery patients required.

\section{Neutrophil Adhesion}

The adherence of neutrophils to endothelial surfaces requires the functioning of two classes of cell surface receptors, the selectins, associated with neutrophil rolling on endothelial surfaces, and the integrins, associated with firm adherence to endothelial surfaces. ${ }^{25}$ The integrins are composed of three heterodimeric glycoproteins: CDlla/CD18, CDllb/CDl8, and $\mathrm{CDllc} / \mathrm{CD} 18 .{ }^{26}$ The role of these adhesion molecules has been studied in a variety of injuries including haemorrhagic shock ${ }^{27}$ and ARDS. ${ }^{28}$ The roles of neutrophil adhesion molecules during $\mathrm{CPB}$ has become increasingly clear in the last few years. In animal models, $\mathrm{CPB}$ induced lung injury is associated with increased $\mathrm{CD} 18$ expression ${ }^{29}$ and, conversely, cardiac performance can be improved by preventing increased surface expression of CD 18. ${ }^{30}$ We therefore measured expression of $\mathrm{CD} 18$ and $\mathrm{CDll}$ on neutrophil cell sur- 
faces. The expression of neutrophil receptors is the direct evidence for their activation. Other indirect evidence includes bactericidal or phagocytic activity and generation of superoxide or elastase. We measured the production of cytokines as the indirect measurement of leukocyte activation. We found that both receptor expressions as well as cytokine production were increased after cardiopulmonary bypass as previously demonstrated by others. $3,5,21,23,24$

Even though the total number of neutrophils was similar between our two groups, we found decreased neutrophil CD18 expression in the group treated with the neutrophil-specific filter. This suggests that the filter had selectively removed those cells with the greater surface expression of CD18. This is similar to our previous finding in canine $C P B$ in which we assessed neutrophil activation by chemiluminescence and found that the overall numbers of activated neutrophils was reduced by the filters. ${ }^{15}$ These filters do not remove neutrophils by virtue of a specific ligand-receptor interaction and, therefore, we do not hypothesize that the filters are truly selective for neutrophils with increased $\mathrm{CD} 18$ expression. Instead, we believe that the increased CD18 expression is a marker of increased neutrophil activation. In turn, activated neutrophils have been shown to be less deformable than quiescent cells ${ }^{31}$ and this is the likely mechanism by which the filters could more selectively remove cells with increased CD18 expression. We wondered if the decreases in numbers of activated neutrophils alone would be sufficient to result in clinical differences between the two groups. The following outcomes were assessed:

\section{Clinical and Biochemical Outcomes}

We specifically evaluated circulating concentrations of IL-6 and IL-8 since they have been reported to increase following CABG surgery and they can influence two of our major outcome measurements, cardiac function (IL- $6^{4}$ ) and neutrophil recruitment $\left(\right.$ IL-8 ${ }^{5}$ ). To ensure that our measurement of IL-6 was not masked by production of binding proteins we also measured IL-6SR. ${ }^{32} \mathrm{We}$ found that concentrations of IL- 6 and IL- 8 were elevated after surgery but the concentrations were similar in the two groups. Therefore, differences in these pro-inflammatory cytokines could not account for any of our results.

We did not find any differences in our clinical endpoints berween the two groups up to the time of discharge. Our sample size was chosen to be able to find clinically important changes in mean arterial pressure or gas exchange but we did not find any haemodynamic differences between the two groups. This is different from our previous study ${ }^{10}$ in patients undergoing coronary artery bypass $(n=32)$ where we found improvements in haemodynamic variables and gas exchange early following admission to ICU. The decline in spirometric values was similar between groups as was the extent of lung atelectasis. Gas exchange, assessed by intrapulmonary shunt and $\mathrm{A}-\mathrm{aDO}_{2}$, was also similar between groups. Reversible cardiac dysfunction has been previously found using echocardiography in patients undergoing CABG surgery. ${ }^{34}$ We wondered if this defect might be associated with activation of neutrophils and if it might be ameliorated by a neutrophil filter. Therefore, in this current study we also examined cardiac performance non-invasively by echocardiography. Although we found a transient deterioration in FAS and EF, these deficits were similar between groups. Our study does not exclude that this defect in cardiac performance is neutrophil related but it does demonstrate that this neutrophil-specific filter will not ameliorate it. None of the patients developed clinical evidence of pneumonia based upon previously described criteria. ${ }^{33}$ Finally, the durations of total hospital stay and Intensive Care Unit stay were similar in both groups.

Leukocyte depletion using plasmapheresis has been previously shown to improve postoperative oxygenation in patients undergoing cardiopulmonary bypass. ${ }^{22}$ Although animal studies have demonstrated prolonged cardiorespiratory advantages, human studies have only demonstrated transient advantages of leukocyte filters. ${ }^{10,17}$ The absence of even transient improvement in the leukocyte filter group, as noted in our previous study, ${ }^{14}$ may be reflective of a saturation of the filter with increased extracorporeal circulation time in this group of valve open heart surgery.

\section{Limitations}

We did not control for individual practice variation between our two surgeons or anaesthetists. We have previously noted the absence of effect of surgeon in coronary artery bypass patients with or without filter. ${ }^{10}$ Anaesthetic agents have not been shown to effect outcomes ${ }^{35}$ in patients undergoing coronary artery bypass surgery, however, we can not preclude that a combination of filter/anaesthetic technique had some effect that neither in isolation exerted. We feel this possibility is less likely.

\section{Summary}

We have demonstrated that a neutrophil filter attached to the extracorporeal oxygenator decreases the extent of CD18 expression on circulating neutrophils likely by selectively removing activated cells. This decrease in activated circulating neutrophils was not associated with any 
demonstrable clinical improvement. Unlike a previous study showing moderate early haemodynamic improvement in patients undergoing CABG surgery, this current study in higher-risk patients did not find haemodynamic improvement or other evidence of clinical efficacy. The difference between the two studies may merely reflect the longer extracorporeal perfusion time required by the patients in this current study. It is possible that more effective filters removing a greater total number of neutrophils might be of clinical benefit but until they are available we conclude that this current neutrophil filter is of no benefit in elective valvular surgery.

\section{Acknowledgements}

We would like to thank Anita Zacharias and Kathleen Brown for their expert clerical assistance, Maria Pisz for her technical assistance and the staff of the Royal University Hospital in Saskatoon for their co-operation. The study was supported in part by a grant from the Saskatchewan Lung Association.

\section{References}

1 Kirklin JK, Blackstone EH, Kirklin JW. Cardiopulmonary bypass: studies on its damaging effects. Blood Purif 1987; 5: 168-78.

2 Westaby S. Organ dysfunction after cardiopulmonary bypass. A systemic inflammatory reaction initiated by the extracorporeal circuit. Intensive Care Med 1987; 13: 89-95.

3 Downing SW, Edmunds LH Jr. Release of vasoactive substances during cardiopulmonary bypass. Ann Thorac Surg 1992; 54: 1236-43.

4 Finkel MS, Hoffman RA, Shen L, Oddis CV, Simmons $R L$, Hattler BG. Interleukin-6 (IL-6) as a mediator of stunned myocardium. Am J Cardiol 1993; 71 : 1231-2.

5 Finn A, Naik S, Klein N, Levinsky RJ, Strobel S, Elliott $M$. Interleukin-8 release and neutrophil degranulation after pediatric cardiopulmonary bypass. J Thorac Cardiovasc Surg 1993; 105: 234-41.

6 Ratliff NB, Young WG Jr, Hackel DB, Mikat E, Wilson $J W$. Pulmonary injury secondary to extracorporeal circulation. An ultrastructural study. J Thorac Cardiovasc Surg 1973; 65: 425-32.

7 Genco CM, Connolly RJ, Peterson MB, et al. Granulocyte sequestration and early failure in the autoperfused heart-lung preparation. Ann Thorac Surg 1992; 53: 217-26.

8 Myers ML, Webb C, Moffat M, McIver D, Del Maestro $R$. Activated neutrophils impair rabbit heart recovery after hypothermic global ischemia. Ann Thorac Surg 1992; 53: 247-52.

9 Litt MR, Jeremy RW, Weisman HF, Winkelstein JA, Becker $L C$. Neutrophil depletion limited to reperfusion reduces myocardial infarct size after 90 minutes of ischemia. Evidence for neutrophil-mediated reperfusion injury. Circulation 1989; 80: 1816-27.

10 Johnson D, Thomson D, Mycyk T, Burbridge B, Mayers I. Depletion of neutrophils by filter during aortocoronary bypass surgery transiently improves postoperative cardiorespiratory status. Chest $1995 ; 107: 1253-9$.

11 Mazer CD, Byrick RJ, Sibbald WJ, et al. Postoperative utilization of critical care services by cardiac surgery: a multicentre study in the Canadian healthcare system. Crit Care Med 1993; 21: 851-9.

12 Tuman KJ, McCarthy RJ, March RJ, Najafi $H_{\text {, }}$ Ivankovich $A D$. Morbidity and duration of ICU stay after cardiac surgery. A model for preoperative risk assessment. Chest 1992; 102: 36-44.

13 Proudfit WL. Grading angina pectoris: comment on the Canadian System (Editorial). Can J Cardiol 1986; 2: 62-3.

14 Teichbolz LE, Kreulen T, Herman MV, Gorlin R. Problems in echocardiographic volume determinations: echocardiographic-angiographic correlations in the presence or absence of asynergy. Am J Cardiol 1976; 37: 7-11.

15 Jobnson D, Thomson D, Hurst $T$, et al. Neutrophilmediated acute lung injury after extracorporeal perfusion. J Thorac Cardiovasc Surg 1994; 107: 1193-202.

16 Palanzo DA, Manley NJ, Montesano RM, Yeisley GL, Gordon D. Clinical evaluation of the LeukoGuard (LG-6) arterial line filter for routine open-heart surgery. Perfusion 1993; 8: 489-96.

$17 G u$ YJ, deVries AJ, Boonstra PW, van Oeveren $W$. Leukocyte depletion results in improved lung function and reduced inflammatory response after cardiac surgery. J Thorac Cardiovase Surg 1996; 112: 494-500.

18 Rinder CS, Rinder HM, Smith BR, et al. Blockade of $\mathrm{C} 5 \mathrm{a}$ and $\mathrm{C} 5 \mathrm{~b}-9$ generation inhibits leukocyte and platelet activation during extracorporeal circulation. J Clin Invest 1995; 96: 1564-72.

19 Chenoweth DE, Cooper SW, Hugli TE, et al. Complement activation during cardiopulmonary bypass. N Eng J Med 1981; 304: 497-503.

20 Schmid-Schonbein $G W$. Capillary plugging by granulocytes and the no-reflow phenomenon in the microcirculation. Federation Proceedings 1987; 46: 2397-401.

21 Bando $K$, Pillai $R$, Cameron $D E$, et al. Leukocyte depletion ameliorates free radical-mediated lung injury after cardiopulmonary bypass. J Thorac Cardiovasc Surg 1990; 99: 873-7.

22 Davies GG, Wells DG, Mabee TM, Sadler R, Melling $N J$. Platelet-leukocyte plasmapheresis attenuates the deleterious effects of cardiopulmonary bypass. Ann Thorac Surg 1992; 53: 274-7. 
23 Breda MA, Drinkwater DC, Laks $H$, et al. Prevention of reperfusion injury in the neonatal heart with leukocyte-depleted blood. J Thorac Cardiovasc Surg 1989; 97: 654-65.

24 Bryne JG, Appleyard RF, Lee CC, et al. Controlled reperfusion of the regionally ischemic myocardium with leukocyte-depleted blood reduces stunning, the no-reflow phenomenon, and infarct size. J Thorac Cardiovasc Surg 1992; 103: 66-72.

25 MacNee W, Selby C. Neutrophil traffic in the lungs: role of haemodynamics, cell adhesion, and deformability. Thorax 1993; 48: 79-88.

26 Arnaont $M A$. Structure and function of the leukocyte adhesion molecules CD11/CD18. Blood 1990; 75: 1037-50.

27 Mileksi WJ, Winn RK, Vedder NB, Pohlman TH, Harlan $J M$, Rice $C L$. Inhibition of CD18- dependent neutrophil adherence reduces organ injury after hemorrhagic shock in primates. Surgery 1990; 108: 206-12.

28 Mulligan MS, Polley MJ, Bayer RJ, Nunn MF, Paulson $J C$, Ward $P A$. Neutrophil-dependent acute lung injury. Requirement for P-selectin (GMP-140). J Clin Invest 1992; 90: 1600-7.

29 Dreyer WJ, Michael LH, Millman EE, Berens KL. Neutrophil activation and adhesion molecule expression in a canine model of open heart surgery with cardiopulmonary bypass. Cardiovasc Res 1995; 29: 775-81.

30 Wilson I, Gillinov AM, Curtis WE, et al. Inhibition of neutrophil adherence improves postischemic ventricular performance of the neonatal heart. Circulation. 1993; 88 Part II: 372-9.

31 Buttrum SM, Drost EM, MacNee W, et al. Rheological response of neutrophils to different types of stimulation. J Appl Physiol 1994; 77 : 1801-10.

32 Müllberg J, Schooltink $H$, Stoyan $T$, et al. The soluble interleukin- 6 receptor is generated by shedding. Eur J Immunol 1993; 23: 473-80.

33 Johnson D, Kelm C, To T, et al. Postoperative physical therapy after coronary artery bypass surgery. Am J Respir Crit Care Med 1995; 152: 953-8.

34 Gorcsan J III, Diana P, Lee J, Katz WE, Hattler BG. Reversible diastolic dysfunction after successful coronary artery bypass surgery. Assessment by transesophageal Doppler echocardiography. Chest 1994; 106: 1364-9.

35 Tuman KJ, McCarthy RJ, Spiess BD, DaValle $M$, Dabir $R$, Ivankovich $A D$. Does choice of anesthetic agent significantly affect outcome after coronary artery surgery? Anesthesiology 1989; 70: 189-98.

\author{
Abbreviations: \\ $\mathrm{CABG}=$ coronary artery bypass graft \\ $\mathrm{CPB}=$ cardiopulmonary bypass \\ IL-6 = interleukin 6 \\ IL-8 = interleukin 8 \\ $\mathrm{P}_{\mathrm{SA}}=$ systemic arterial pressure \\ $\mathrm{P}_{\mathrm{RA}}=$ right atrial pressure \\ $\mathrm{P}_{\mathrm{PA}}=$ pulmonary artery pressure \\ $\mathrm{P}_{\mathrm{CWP}}=$ pulmonary capillary wedge pressure \\ $\mathrm{CI}=$ cardiac index \\ $\mathrm{WBC}=$ white blood cell count \\ IL-6SR = interleukin 6 soluble receptor \\ FAS $=$ fractional shortening \\ $\mathrm{EF}=$ ejection fraction \\ $\mathrm{A}-\mathrm{aDO} \mathrm{O}_{2}=$ aveolar to arterial difference for oxygen \\ $\dot{\mathrm{Q}} \mathrm{s} / \dot{\mathrm{Q}}^{2}=$ intrapulmonary shunt
}

